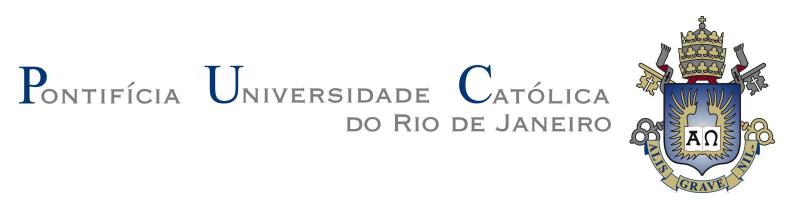

Vitor de Azevedo Lopes

\title{
Mashup e o Novo Jeito de Criar no Século XXI
}

Dissertação de mestrado

Dissertação apresentada como requisito parcial para obtenção do grau de Mestre pelo Programa de Pós-Graduação em Literatura, Cultura e Contemporaneidade do Departamento de Letras do Centro de Tecnologia e Ciências Humanas da PUC-Rio.

Orientador: Prof. Júlio Cesar Valladão Diniz

Rio de Janeiro Abril de 2015 


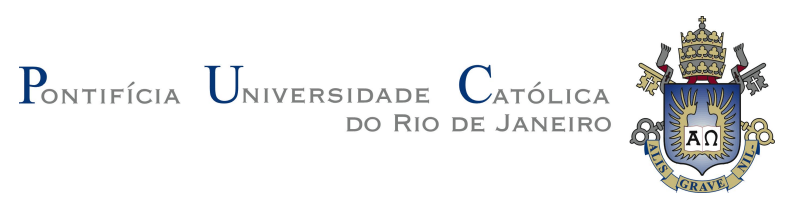

VITOR DE AZEVEDO LOPES

\section{MASHUP E O NOVO JEITO DE CRIAR NO SÉCULO XXI}

Dissertação apresentada como requisito parcial para obtenção do grau de Mestre pelo Programa de PósGraduação em Literatura, Cultura e Contemporaneidade do Departamento de Letras do Centro de Tecnologia e Ciências Humanas da PUC-Rio. Aprovada pela Comissão Examinadora abaixo assinada.

Prof. Júlio Cesar Valladão Diniz

Orientador

Departamento de Letras - PUC-Rio

Prof. Miguel Jost Ramos Bolsista Pós-Doutorado PUC-Rio/PNPD

Prof. Paulo da Costa e Silva Franco de Oliveira Universidade Federal do Rio de Janeiro

Profa. Denise Berruezo Portinari Coordenadora Setorial do Centro de Teologia e Ciências Humanas - PUC-Rio

Rio de Janeiro, 14 de abril de 2015 
Todos os direitos reservados. É proibida a reprodução total ou parcial do trabalho sem autorização do autor, do orientador e da universidade.

\section{Vitor de Azevedo Lopes}

Graduou-se em Comunicação Social/Jornalismo, pela Universidade Federal do Espírito Santo, em 2007. Foi coordenador de Jornalismo da Rádio Universitária 104.7 FM, em Vitória-ES. Foi curador das quatro edições do Seminário Música Livre. Foi Consultor Analista para a elaboração do Plano Municipal de Cultura de Vitória-ES, pelo Ministério da Cultura. Foi curador e membro do júri de premiação de diversas edições do festival de cinema Vitória Cine Vídeo. É produtor e curador do programa multimídia Infinitas e também dos festivais. Lab Infinitas. É autor do livro infantil Encolhe, Tempo (2011, Ed. Saraiva).

Ficha catalográfica

Lopes, Vitor de Azevedo

Mashup e o novo jeito de criar no século XXI / Vitor de Azevedo Lopes; orientador: Júlio Cesar Valladão Diniz. -2015 .

113 f. : il. (color.) ; $30 \mathrm{~cm}$.

Dissertação (Mestrado) - Pontifícia Universidade Católica do Rio de Janeiro, Departamento de Letras, 2015.

Inclui bibliografia.

1. Letras - Teses. 2. Mashup. 3. Internet. 4. MP3. 5. Indústria Fonográfica. 6. Download. I. Diniz, Júlio Cesar Valladão. II. Pontifícia Universidade Católica do Rio de Janeiro. Departamento de Letras. III. Título.

CDD: 800 


\section{Agradecimentos}

Para os que virão.

Ao meu orientador, Júlio Cesar Valladão Diniz, pelo incentivo e inspiração intelectual ao longo dos anos.

Ao Miguel Jost, pelas provocações de vida que indicaram novos rumos de pensamento.

À minha mãe, pelo incentivo.

À minha família, pelo apoio de sempre.

Aos amigos de Vitória, pela família construída.

Aos amigos do Rio de Janeiro, pelas descobertas e distância encurtada.

À Paula Falcão, pelo carinho e apoio.

Ao Fabrício Noronha, pelas inspirações e modo de ver a vida.

Aos amigos de Lab.Muy, porque ter uma empresa com amigos ao lado é muito mais divertido.

À Amora, que sonolentamente me acompanhou no processo de escrita.

A todas as fontes, coautoras desta pesquisa comigo.

E, novamente, a todos que me fizeram sorrir nessas "horinhas de descuido". 


\section{Resumo}

Lopes, Vitor de Azevedo; Diniz, Júlio Cesar Valladão. Mashup e o novo jeito de criar no século XXI. Rio de Janeiro, 2015. 113p. Dissertação de Mestrado - Departamento de Letras, Pontifícia Universidade Católica do Rio de Janeiro.

O mashup, estilo musical popularizado a partir dos primeiros anos do século XXI, ilustra como a democratização do acesso à internet e também aos softwares de download e edição de música em arquivo digital trouxe o ouvinte/usuário para o protagonismo nas novas formas de composição. Com o advento de programas como o Napster e outras redes de trocas de arquivo em MP3, o cidadão teve acesso a ferramentas diversas e reconfigurou a noção de produção musical, além de, naquele momento, instaurar outros ambientes de interação social. O mashup, um dos principais campos estéticos em que ficaram claros esses meios de criação, consiste em escolher trechos de duas ou mais músicas e recombiná-las a partir da junção delas, criando uma terceira composição. Ficam estabelecidos, assim, outros meios de apropriação e uso de bens culturais, deslocando sentidos como autoria, originalidade, cópia e produção artística. Deste modo, as tecnologias disponíveis possibilitam o surgimento de artistas que criam com as obras de outros, recombinando criações para o surgimento de novos discursos. É a partir dos mashups que se busca enxergar uma geração calcada em novos modos de se relacionar tanto entre si quanto com osbens culturais produzidos e divulgados pela internet.

\section{Palavras-chave}

Mashup; internet; MP3; indústria fonográfica; download 


\section{Abstract}

Lopes, Vitor de Azevedo; Diniz, Júlio Cesar Valladão (Advisor). Mashup and the new way to create in the XXI century. Rio de Janeiro, 2015. 113p. MSc. Dissertation - Departamento de Letras, Pontifícia Universidade Católica do Rio de Janeiro.

Mashup, a musical genre popularized at the beginning of the XXI century, illustrates how the democratization of access to the Internet as well as to software downloads and to digital music publishing brought the listener/user to the role of new methods of music composition. With the advent of programs such as Napster and other MP3 file sharing networks, citizens had access to a wide range of tools, reconfiguring the notion of music production, and also bringing up other social interaction environments. Mashup, one of the main aesthetic fields in which these ways of creating became clear, consists of excerpts chosen from two or more songs which are recombined, originating a third one. Thenceforth other means of appropriation and also of making use of cultural goods have been established, moving senses of authorship, originality, copy and artistic production. Thus these available technologies allow the emergence of artists who create using someone else's work, recombining these creations to raise other kind of discourses. It is from the mashups that it is aimed to understand one generation that is developed in new ways of relationships between each other as much as of enjoying cultural goods produced and spread out on the Internet.

\section{Keywords}

Mashup; internet; MP3; recording industry; download 


\section{Sumário}

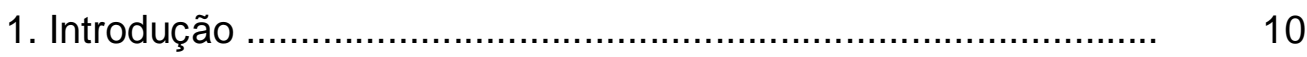

2. Capítulo - Download do Arquivo ………………………........ 15

3. Capítulo - Editando Arquivo........................................................

4. Capítulo - Subindo para a Internet............................................... 65

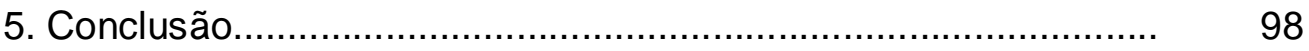

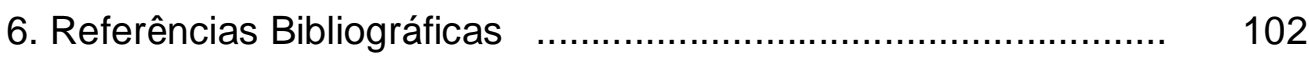

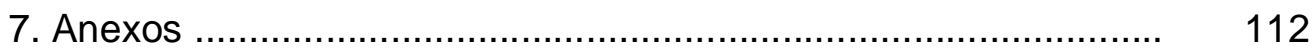




\section{Lista de figuras}

Figura 01 - Post do Facebook de Dilma Rousseff 66

Figura 02 - Visão parcial do canal de Faroff no Youtube 72 
O quereres e o estares sempre a fim Eu quero entrar na rede pra contactar (Caetano Veloso vs. Gilberto Gil) 